\title{
The enigma of the pathogenesis of the Jarisch-Herxheimer reaction
}

\author{
IRIS K. ARONSON AND KEYOUMARS SOLTANI \\ Section of Dermatology, Department of Medicine, The University of Chicago Pritzker School of Medicine, \\ Chicago, Illinois, U.S.A.
}

\section{Clinicopathological aspects}

The pathophysiological mechanisms of the JarischHerxheimer reaction (JHR) have remained obscure since its original recognition. In light of the many recent advances in various areas of immunobiology it is felt that the JHR merits brief review and reevaluation of pathogenesis.

The JHR was first described in 1895 by Jarisch and in 1902 by Herxheimer and Krause as a transient exacerbation in the appearance of the mucocutaneous lesions of early syphilis after starting treatment with mercury. Subsequently the reaction was described after treatment of the disease with arsenic, bismuth, and more recently with penicillin and immune serum (Rook, Wilkinson, and Ebling, 1972; Sheldon, Heyman, and Evans, 1951).

The JHR occurs in both seronegative and seropositive phases of primary syphilis. It occurs in 55 per cent. of seronegative patients and 95 per cent. of sero-positive cases (Putkonen, Solo, and Mustakallio, 1966). In early secondary syphilis the incidence of JHR is as high as in seropositive primary syphilis (Putkonen and Rehtijärvi, 1950). The incidence decreases in the late secondary stage and JHR is not usually found in latent syphilis. In general paresis (dementia paralytica) an incidence of 75 per cent. or higher has been reported, while in other types of neurosyphilis the frequency varies from 12 to 25 per cent. (Hoekenga and Farmer, 1948). In neurosyphilis the incidence of the JHR has been reported to be higher in patients with more severe abnormalities in the cerebrospinal fluid (Putkonen and Rehtijärvi, 1951). The occurrence of the JHR in cardiovascular syphilis has been difficult to document. In patients who survive, the reaction obviously cannot be histologically confirmed, and in the other patients acute histological changes disappear by the time they die of complications (Whorton and Dekham, 1951). A patient with involvement of the aorta was recently reported to have died $27 \mathrm{hrs}$ after penicillin therapy

Received for publication March 1, 1976

Address for reprints: Dr K. Soltani, M.D., 950 East 59th Street, Box 409, Chicago, Illinois 60637, USA

This work was supported in part by The Louis Block Fund, The University of Chicago without showing a febrile reaction. Post mortem studies revealed a marked acute inflammatory reaction at the site of aortic involvement. In congenital syphilis the JHR occurs more frequently in patients under 6 months of age (Putkonen, 1950).

JHR is rare in late congenital syphilis. We reviewed sixteen patients with late congenital syphilis treated at the University of Chicago Hospitals and Clinics in the past three decades. Of the sixteen patients, fourteen were females and two were males and their ages ranged between 19 and 46 years. All these patients had some degree of deafness with or without other components of Hutchinson's triad. One patient also had the Vogt-Koyanagi syndrome. Treatment consisted of heavy metals (in 2 patients), heavy metals and penicillin (2), penicillin (7), penicillin and ACTH (4), and fever therapy (1). A retrospective study of the records failed to reveal any evidence of JHR in any of these patients.

The clinical manifestations of the JHR include fever (temperatures of $38^{\circ} \mathrm{C}$ higher), chills, and exacerbation of the lesions (Pinkus, 1911; Sheldon and Heyman, 1949). In more severe reactions, headache, sore throat, malaise, myalgia, arthralgia, nausea, and vomiting occur with varying incidence (Skog and Gudjónsson, 1966; Schofield, Talbot, Bryceson, and Parry, 1968; de Graciansky and Grupper, 1961).

The pattern of febrile reaction has been extensively studied in both early and late syphilis. In early disease fever starts about $4 \mathrm{hrs}$ after initiation of therapy, reaches a peak at approximately $8 \mathrm{hrs}$, and subsides by $16 \mathrm{hrs}$ (Sheldon and Heyman, 1949). In neurosyphilis the earliest rise in temperature may occur at $4 \mathrm{hrs}$, reaching a maximum from 6 to $24 \mathrm{hrs}$ after treatment starts (6 to $10 \mathrm{hrs}$ in 20 per cent., 12 to $16 \mathrm{hrs}$ in 50 per cent, and 18 to $24 \mathrm{hrs}$ in 30 per cent. of patients: Hoekenga and Farmer, 1948). All patients have a normal temperature at $36 \mathrm{hrs}$. The latter occurrence of maximal fever in neurosyphilis has been attributed to a delayed penetration of pencillin into the central nervous system (Putkonen and Rehtijärvi, 1951). A double febrile reaction has been reported in both adults and children who have received an initial low dose of penicillin $(5000 \mathrm{u}$. in 
children and less than $20 \mathrm{u} . / \mathrm{kg}$. in adults), followed by larger amounts of the drug (Putkonen, 1950; Gudjónsson and Skog, 1968).

In a case of secondary syphilis with hepatitis, rises in SGOT and SGPT were noted after treatment although alkaline phosphatase and bilirubin levels remained unchanged. A liver biopsy specimen revealed non-specific inflammatory findings with no treponemes demonstrable in the tissue (Young, Bahr, and Waye, 1974).

In a patient with early syphilis who had no urinary abnormalities, penicillin therapy resulted in a severe febrile reaction and the development of nephrotic syndrome which subsided spontaneously. It was suggested that the JHR occurred in the renal parenchyma which was involved without any clinical manifestations (Scott and Clark, 1946). Renal involvement, of course, can also occur in untreated cases of early syphilis (Gamble and Reardan, 1975).

Histological changes in the JHR have been studied by several investigators. Sheldon and Heyman (1949) found transient acute inflammatory changes in the syphilitic lesions of both human subjects and rabbits 4 to $6 \mathrm{hrs}$ after the beginning of treatment. Dilatation of the capillaries and venules was followed by endothelial swelling and migration of leucocytes through vessel walls into the surrounding oedematous tissues. The inflammation subsided within $18 \mathrm{hrs}$ without significant degenerative changes of the vessel walls or intravascular thrombus formation. Histological findings in biopsy specimens obtained at $72 \mathrm{hrs}$ resembled those of the pretreatment specimens. In a number of patients with equivocal symptoms of the JHR, similar histological changes were detectable. Thus the histological findings are a more sensitive indicator of the JHR, especially in the clinically undetectable forms of this reaction. Sheldon and Heyman produced the JHR by the administration of pooled immune serum to syphilitic rabbits. The histological changes were found to be similar to those observed after arsenical or penicillin therapy and occurred at the same time intervals (Sheldon and others, 1951).

Peripheral leucocytosis with lymphopenia occurs with the fever in this reaction (Skog and Gudjónsson, 1966).

\section{Pathogenesis}

Several mechanisms have been suggested for the pathogenesis of the JHR. Some investigators, including Herxheimer, attributed the JHR to the release of treponemal breakdown substances. These products were thought to react with the sensitized syphilitic tissue resulting in exacerbation of the lesions after therapy (Sheldon and Heyman, 1949). Most investigators agree that the direct effect of the endotoxin on the tissues is by itself insufficient to cause the JHR, otherwise the incidence and severity of the reaction would always depend on the number of treponemes in a given individual at the time of treatment and the quantity of the micro-organisms destroyed by specific therapy. Also the reaction occurs in late syphilis where the number of treponemes could be very small (Skog and Gudjónsson, 1966). Schofield and others (1968) attribute the fever to the release of leucocyte endogenous pyrogen by the treponemal endotoxin.

Direct vasotoxic action of the drug on the tissue as a mechanism of the JHR was a prominent theory in the past when metal therapy was the primary mode of treatment. The theory of vasotoxicity was later abandoned when the JHR was induced by the administration of pooled immune serum in rabbits with experimental syphilis, and especially with the advent of penicillin which did not show direct vasotoxic effect in other diseases (Sheldon and others, 1951).

The failure of antihistaminic drugs to block the JHR suggests that the release of histamine is not a major factor in the production of the reaction (Heyman, Sheldon and Evans, 1952; Zachariae and Nielsen, 1974). Zachariae and Nielsen's investigation did not document the release of plasma kinins by Hageman factor activation after the release of large amounts of spirochaetal substances in the JHR.

Similarities in the histological picture of the JHR and cell-mediated immune reactions in the skin have been noted by several investigators. However, the JHR does not exactly correlate with the time course of cell-mediated immune reactions because it begins approximately $4 \mathrm{hrs}$ after the start of treatment and is usually over by $24 \mathrm{hrs}$ (Sheldon and Heyman, 1949). There is some experimental evidence to support the speculation that cell-mediated immunity plays an important role in the immune reactions in syphilis. Using Reiter protein, macrophage inhibition factor (MIF) production by lymphocytes has been studied in various phases of syphilis. Inhibition of migration in cases of active late syphilis as compared to the lack of inhibition in primary syphilis supports the concept of the operation of delayed hypersensitivity in late active syphilis (Levene, Turk, Wright, and Grimble, 1969). As in chronic mucocutaneous candidosis, a dissociation phenomenon in cell-mediated immunity has been reported in secondary syphilis in the form of absence of MIF production in the presence of a positive lymphocyte transformation response to Reiter protein antigen (Fulford and Brostoff, 1972). Furthermore, Levene and others (1969), found a significant reduction in lymphocyte transformation response to PHA in patients with primary and secondary syphilis. Plasma from patients with secondary syphilis, moreover, suppressed transformation of normal lymphocytes. Such an inhibitory effect of plasma was not detected in either primary or latent 
syphilis. Treponemal products or a circulating anti-lymphocyte autoantibody have been thought to inhibit the normal lymphocyte transformation response in secondary syphilis. Such factors which could impair cell-mediated immunity may lead to increased proliferation of the organisms so that they or their soluble products can combine with circulating antibodies. Levene and others (1969) suggest that such immune complexes might precipitate the clinical manifestations of secondary syphilis, many of which resemble those found in chronic serum sickness. Unlike the case in syphilitic renal disease, direct immunofluorescence examinations have not so far demonstrated such immune complex deposits in cutaneous lesions (Smith, Bartruff, and Blanchard, 1970). Depleting syphilitic animals of complement or circulating antibodies or the use of the ALS or drugs which modify leucocyte function before penicillin therapy may help to define the role of the various immunological components in the pathogenesis of the JHR.

The effects of systemically administered glucocorticosteroids in the JHR have been studied by some investigators (de Graciansky and Grupper, 1961). With preventive steroid therapy the incidence of febrile reaction was reduced significantly. Despite the suppression of febrile response, the characteristic changes in leucocyte pattern are not affected by steroids. Also the macular rash was intensified in a patient who had received a prophylactic dose of $40 \mathrm{mg}$. prednisone and had no rise in temperature (Gudjónsson and Skog, 1968). It was thus concluded that systemic corticosteroids mainly influence the febrile component of the JHR in early syphilis. However, in active late syphilis, the administration of steroids may have more significant suppressive effects on the inflammatory components of the JHR.

\section{References}

DE Graciansky, P., and Grupper, C. (1961) Brit. F. vener. Dis., 37, 247

FulFord, K. W. M., and BrostofF, J. (1972) Ibid., 48, 483

Gamble, C. N., and Reardan, J. B. (1975) New Engl. f. Med., 292, 449

Gudjónsson, H., and Skog, E. (1968) Acta derm.venereol. (Stockh.), 48, 15

Heyman, A., Sheldon, W. H., and Evans, L. D. (1952) Brit. F. vener. Dis., 28, 50

Hoekenga, M. T., and Farmer, T. W. (1948) Arch. intern. Med., 82, 611

LeVENE, G. M., TURK, J. L., WRIGHT, D. J. M., and GrIMBLE, A. G. S. (1969) Lancet, 2, 246

Pinkus, F. (1911) Der. Ztschr., 18, 672

Putkonen, T. (1950) Dermatologica, 101 (6), 313

and ReHTIJÄRVI, K. (1950) Acta derm.-venereol. (Stockh.), 30, 503

- - , (1951) Ibid., 31, Suppl. 24, p. 120

- Solo, O. P., and Mustakallio, K. K. (1966) Brit. $\mathcal{F}$. vener. Dis., 42, 181

Rook, A., Wilkinson, D. S., and Ebling, F. J. G. (1972) 'Textbook of Dermatology', 2nd ed., p. 666. Blackwell Scientific Publications, Oxford

Schofield, T. P. C., Talbot, J. M., Bryceson, A. D. M., and ParRY, E. H. O. (1968) Lancet, 1, 58

Scott, V., and Clark, E. G. (1946) Amer. F. Syph., 30, 463

Sheldon, W. H., and Heyman, A. (1949) Ibid., 33, 213

$\longrightarrow,-1$ and Evans, L. D. (1951) Ibid., 35, 4

Skog, E., and Gudjónsson, H. (1966) Acta derm.venereol. (Stockh.), 46, 136

SMITH, E. B., BarTRUFF, J. K., and Blanchard, V. (1970) Brit. F. vener. Dis., 46, 426 (letter)

Whorton, C. M., and Dekham, S. W. (1951) Amer. F. Syph., 35, 255

Young, E., Bahr, G., and Waye, J. D. (1974) Amer. $\mathcal{F}$. Gastroenterol., 61, (6), 476

Zachariae, H., and Nielsen, E. (1974) Acta derm.venereol. (Stockh.), 54, 401 